\title{
Comparison of the knowledge, attitudes toward, and practices of contraception between Thai Muslim women living in Bangkok and those living in the southernmost provinces of Thailand
}

\author{
Jureeporn Saelim ${ }^{\mathrm{a}}$, Somsook Santibenchakul ${ }^{\mathrm{b}}$, Unnop Jaisamrarn ${ }^{\mathrm{a}}$ \\ ${ }^{a}$ Department of Obstetrics and Gynecology, Faculty of Medicine, Chulalongkorn University, Bangkok \\ 10330, Thailand \\ ${ }^{b}$ Family Planning and Reproductive Health Unit, Department of Obstetrics and Gynecology, King \\ Chulalongkorn Memorial Hospital, Bangkok 10330, Thailand
}

\begin{abstract}
Background: There are limited data on the use of contraception by Thai Muslim women.
Objectives: To compare and explore the knowledge, attitudes toward, and practices (KAP) of contraception between Thai Muslim women living in Bangkok and those living in the Southernmost provinces. Variables associated with KAP were also examined.

Methods: This was a community-based cross-sectional study, which was conducted in the Muslim communities in Bangkok and those in the southernmost provinces of Thailand including Yala, Pattani, and Narathiwat. A multistage, cluster sampling technique was used to identify participants. Only literate Thai Muslim women who lived in their hometown, and aged between 15-49 years were included in the analysis. A self-administered questionnaire was used to assess participants' KAP of contraception.

Results: Data from 423 participants were analyzed. Knowledge and attitude scores between the two groups were comparable. A higher proportion of women from the southernmost provinces used contraceptives. However, when a multivariate regression model was used to adjust for other variables, women's geographical residence was not associated with higher knowledge and attitude scores, or contraceptive practices. College-level education and higher income level were independent factors associated with contraceptive knowledge. A higher knowledge score was independently related to a positive attitude towards contraception. Only number of children and income level were independently associated with contraceptive practices.

Conclusions: For Thai Muslim women, geographical residence was not significantly associated with KAP of contraception. The educational level, income level, and number of children of the women played major roles in KAP of contraception.
\end{abstract}

Keywords: Attitude, contraceptive practices, KAP, knowledge, Muslim

Even though the use of contraception in Thailand has a prevalence of as high as $79.6 \%$, there is still a proportion of women in certain regions of the country that do not use contraception [1]. The 2009 Reproductive Health Survey, conducted by the Thai National Statistical Office, revealed that the proportion of married women, aged between 15-49 years who use contraception was lowest among women who lived in the southern part of Thailand [1]. A study conducted in the United States found that low use of

Correspondence to: Unnop Jaisamrarn, Department of Obstetrics and Gynecology, Faculty of Medicine, Chulalongkorn University, Bangkok 10330, Thailand. E-mail: Unnop.J@chula.ac.th contraception posed a significant risk factor for unintended pregnancy, which usually ended in abortion [2]. In addition, the 2009 Thailand Reproductive Health Survey showed that the birth rate in the southern region of Thailand was higher than other regions [1]. High birth rate was associated with the number of children and shorter intervals between pregnancies, which can contribute to serious obstetrical and perinatal adverse events. These conditions can be avoided if fertile women who are at risk of unintended pregnancies use contraception.

One quarter of the people living in the southern part of Thailand are Muslims [3] and in the southernmost border provinces, more than $95 \%$ are 
Muslims [4]. It is possible that religion may play a role in the acceptance and use of contraception. The fertility rate of Muslims in the south is higher than that of Buddhists [5]. Despite this, family planning is not forbidden among Muslims and the use of contraception can range from "permissible" to "disapproval" [6]. This indicated that among Islamic women, besides their religious beliefs, other factors may influence decisions by the women on contraceptive practices. Data from hospital statistics of the King Chulalongkorn Memorial Hospital, Bangkok, and Racha Nakarin Hospital, in one of the southernmost provinces of Thailand, Narathiwat, also showed that there were differences in the proportion of mothers with many children between Thai Muslims in Bangkok and Narathiwat $[7,8]$. The proportion of Thai Muslim mothers with a lot of children in Narathiwat was higher than those who lived in Bangkok [7, 8]. Planned pregnancy and appropriate spacing of childbirth, which reproductive aged women can achieve by using contraception, is important for the well-being and health of the women. Therefore, it was recommended that health care providers investigate why these Thai Muslim women were not using contraceptives. Until now, there were limited data on the use of contraception by Thai Muslim women. Therefore, the main objective of this study was to compare and explore knowledge, attitudes toward, and practices (KAP) of contraception between Thai Muslim women living in Bangkok and those living in the southernmost provinces of Thailand. Factors that were associated with the KAP of contraception were also assessed. The KAP model was used because it has served as an insight into communities [9]. It is an appropriate tool with which to explore differences in the levels of knowledge and attitudes, which may affect the decision to use contraception. We ascertained whether the use of contraceptives had any relationship with the Muslim beliefs and practices.

\section{Materials and methods Questionnaire}

Self-administered questionnaire was developed by using the FOG Zone Survey Questionnaire and the book Family Planning: A Global Handbook for Providers (2011 update) as references $[9,10]$. The questionnaire was divided into three parts: demographics, Muslim rituals and practices, and KAP of contraception. Aside from collecting the general information, the first part of the questionnaire also assessed the participant's future plans for having children. The second part of the questionnaire assessed the Muslim rituals and practices of the participant, such as the prayer (salat), alms tax (zakat), fasting during the month of Ramadan (sawm), and pilgrimage to Mecca (hajj). The last part of the questionnaire was divided into 3 subcategories to assess KAP of contraception. To assess the knowledge of contraception, there were 20 true/false statements, which included basic knowledge of how to correctly use contraceptive methods and any misconceptions of using condoms (6 questions), combined oral contraceptive pills (COCs) (6 questions), intrauterine devices (IUD) (5 questions), and depot medroxyprogesterone acetate (DMPA) (3 questions). For each correct answer, a score of 1 would be given. For any incorrect answer, a score of 0 would be given. Six questions assessed the participant's attitude towards using contraception, including the impact of contraception on the health of the women. A Likerttype scale with 4 choices, ranging from a score of 1 , indicating the person had the poorest attitude, to a score of 4 , indicating that the person had the best attitude. The last part of the questionnaire assessed the participant's contraceptive practices and/or lack thereof. Two experts in family planning reviewed and validated the questionnaire's content.

\section{Study design, sampling techniques, and data collection}

This study was a community-based cross-sectional study, which was conducted in the Muslim communities in Bangkok and the southernmost provinces of Thailand including Yala, Pattani, and Narathiwat. A pilot study was conducted in each region, and its results were used to calculate the required sample size for this study. To achieve an $80 \%$ power at a significant level of $5 \%$, a sample size of 176 subjects was required for each group. To address the issue of not responding to the questions, an additional $20 \%$ of the subjects were added to each group. A multistage clustered sampling technique was used to acquire the participants. Briefly, for Bangkok, 2 of 6 Muslim communities were sampled, and then participants were randomly selected from these communities. For the southernmost provinces, one district from each province was sampled, and then subjects were randomly selected from these districts. Only literate Thai Muslim women, ages between 15-49 years were eligible and included in this study. Thai Muslim women who did not live in their hometown were excluded. 
After ethical approval of this study was obtained from the Institutional Review Board committee of the Faculty of Medicine, Chulalongkorn University (certificate of approval No. 358/2014), a selfadministered questionnaire was distributed to participants from June-October 2014 by female research assistants, who were midlevel health care providers already working and providing health care services in those areas. During the regularly scheduled home visits, these research assistants would ask the participants if they wanted to participate in this study. Written informed consent to participate in the study was obtained from all participants. The questionnaire took approximately 15-20 minutes to complete. The questionnaires were collected from November 2014 to March 2015. Because the practice of the religion is a sensitive issue, the research assistants reassured the participants their confidentiality and privacy would be maintained throughout the study.

\section{Statistical analyses}

Descriptive and inferential statistical analyses were conducted using IBM SPSS for Windows version 17 (IBM Corp, Armonk, NY, USA). Mean, standard deviation, frequency, and percentage were used to display continuous and categorical variables respectively. Independent $t$ tests and chi-square tests were used to compare differences in the variables between groups. Univariate and multivariate logistic regression models were used to evaluate factors that contributed to the knowledge, attitude scores, and contraceptive practices.

\section{Results}

A total of 423 participants were included in the analysis. Response rate of the participants, from Bangkok and the southernmost provinces were $86.8 \%(204 / 235)$ and $91.3 \%(219 / 240)$ respectively. The reliability of the questionnaire was statistically established; Pearson score for the knowledge component was 0.58 , and the Cronbach alpha for the attitude component was 0.78 . Figure 1 shows the flow of this study.

Basic characteristics, Muslim rituals, and practices of the participants from both groups are shown in Table 1. Sunni was the main denomination of Islamic women living in both Bangkok and the southernmost provinces. Women in the southernmost provinces were more religious and strict with their practices than those in Bangkok.

Mean knowledge scores of the participants from Bangkok and the southernmost provinces were 13.26/ 20 and 13.09/20 respectively. For the knowledge of contraceptive methods, the 2 groups of participants had the highest score on DMPA and condoms. Attitude scores of the participants, who lived in Bangkok and the southernmost provinces were 15.69/24 and 15.08/24 respectively. There were no significant differences in the knowledge and attitude scores between participants who lived in Bangkok and the 3 southernmost provinces. Contraceptive use of the participants, who lived in Bangkok and 3 southernmost provinces were $57.4 \%(117 / 204)$ and $68.0 \%(149 / 219)$ respectively as shown in Table 2.

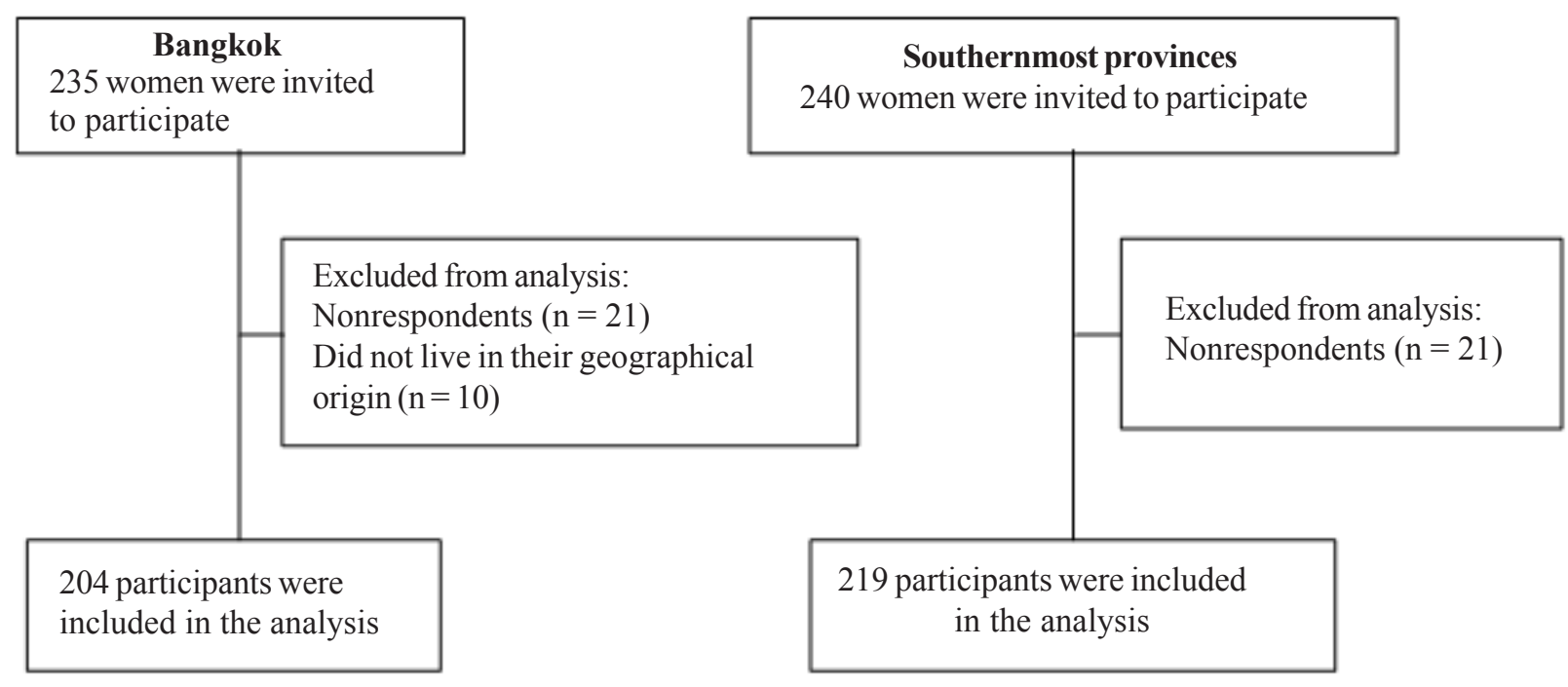

Figure 1. Study flow 
Table 1. Basic characteristics, beliefs and practices of Muslim women living in Bangkok or the southernmost provinces

\begin{tabular}{|c|c|c|c|}
\hline Variables & $\begin{array}{l}\text { Bangkok } \\
(n=204)\end{array}$ & $\begin{array}{l}\text { Southernmost provinces } \\
\qquad(n=219)\end{array}$ & $\boldsymbol{P}$ \\
\hline Age $(\text { years })^{1}$ & $31.8(9.09)$ & $30.2(6.62)$ & 0.05 \\
\hline \multicolumn{4}{|l|}{ Education $^{2}$} \\
\hline Below Bachelor's degree & $126(61.8)$ & $107(48.9)$ & \multirow[t]{2}{*}{0.008} \\
\hline Equal/higher than a Bachelor's degree & $78(38.2)$ & $112(51.1)$ & \\
\hline \multicolumn{4}{|l|}{ Current number of children ${ }^{2}$} \\
\hline 0 & $60(29.4)$ & $56(25.6)$ & \multirow[t]{5}{*}{0.71} \\
\hline 1 & $73(35.8)$ & $74(33.8)$ & \\
\hline 2 & $43(21.1)$ & $49(22.4)$ & \\
\hline 3 & $18(8.8)$ & $25(11.4)$ & \\
\hline$\geq 4$ & $10(4.9)$ & $15(6.8)$ & \\
\hline \multicolumn{4}{|l|}{ Income (Thai baht) ${ }^{2}$} \\
\hline$<5,000$ & $41(20.1)$ & $51(23.3)$ & \multirow[t]{3}{*}{0.04} \\
\hline $5,000-20,000$ & $129(63.2)$ & $149(68)$ & \\
\hline$>20,000$ & $34(16.7)$ & $19(8.7)$ & \\
\hline \multicolumn{4}{|l|}{ Plan to have more children ${ }^{2}$} \\
\hline Yes & $89(43.6)$ & $145(66.2)$ & \multirow[t]{3}{*}{0.001} \\
\hline No & $93(45.6)$ & $42(19.2)$ & \\
\hline Not sure & $22(10.8)$ & $32(14.6)$ & \\
\hline \multicolumn{4}{|l|}{ Denominations of Islam } \\
\hline Sunni & $155(76.0)$ & $205(93.6)$ & \multirow[t]{3}{*}{0.001} \\
\hline Shia & $14(6.9)$ & $1(0.5)$ & \\
\hline Others & $35(17.2)$ & $13(5.9)$ & \\
\hline \multicolumn{4}{|l|}{ Ritual prayer (salat) } \\
\hline $1-4$ & $109(53.4)$ & $11(5.0)$ & \multirow[t]{2}{*}{0.001} \\
\hline 5 & $78(38.2)$ & $204(93.2)$ & \\
\hline \multicolumn{4}{|c|}{ Fasting during the month of Ramadan (sawm) } \\
\hline$<7$ & $11(5.4)$ & $0(0)$ & \multirow[t]{5}{*}{$<0.001$} \\
\hline $7-13$ & $24(11.8)$ & $1(0.5)$ & \\
\hline $14-20$ & $64(31.4)$ & $10(4.6)$ & \\
\hline $21-27$ & $49(24.0)$ & $69(31.5)$ & \\
\hline $28+$ & $56(27.5)$ & $139(63.5)$ & \\
\hline \multicolumn{4}{|l|}{ Alms tax (zakat) } \\
\hline Ever in the past year & $185(90.7)$ & $209(95.4)$ & \multirow[t]{2}{*}{0.05} \\
\hline Never in the past year & $19(9.3)$ & $10(4.6)$ & \\
\hline \multicolumn{4}{|l|}{ Pilgrimage to Mecca (hajj) } \\
\hline Ever in the past year & $194(95.1)$ & $212(96.8)$ & \multirow[t]{2}{*}{0.37} \\
\hline Never in the past year & $10(4.9)$ & $7(3.2)$ & \\
\hline
\end{tabular}


Table 2. Knowledge, attitudes, and practices (KAP) of contraception among Muslim women living in Bangkok or the southernmost provinces

\begin{tabular}{|c|c|c|c|c|}
\hline KAP of contraception & Bangkok & $\begin{array}{c}\text { Southernmost } \\
\text { provinces }\end{array}$ & $\begin{array}{l}\text { Mean difference } \\
(t \text { test) } 95 \% \text { CI }\end{array}$ & $\boldsymbol{P}$ \\
\hline \multicolumn{5}{|l|}{ Knowledge $^{1}$} \\
\hline Condom (6) & $4.52(1.02)$ & $4.37(1.11)$ & $0.16(-0.04,0.36)$ & 0.23 \\
\hline Combined oral contraceptive pills (6) & $3.34(1.28)$ & $3.39(1.22)$ & $-0.05(-0.29,0.19)$ & 0.65 \\
\hline Intrauterine devices (5) & $3.09(0.98)$ & $3.04(0.90)$ & $0.05(-0.13,0.23)$ & 0.57 \\
\hline Depot medroxyprogesterone acetate (3) & $2.31(0.70)$ & $2.29(0.65)$ & $0.02(-0.11,0.15)$ & 0.80 \\
\hline Sum score (20) & $13.26(2.25)$ & $13.09(2.31)$ & $0.17(-0.27,0.61)$ & 0.45 \\
\hline Attitude $^{1}$ (of a total 24 questions) & $15.68(2.35)$ & $15.41(1.97)$ & $0.27(-0.14,0.68)$ & 0.20 \\
\hline \multicolumn{5}{|l|}{ Practice $^{2}$} \\
\hline Used contraceptives & $117(57.4 \%)$ & $149(68 \%)$ & & 0.02 \\
\hline Did not use contraceptives & $87(42.6 \%)$ & $70(32 \%)$ & & \\
\hline \multicolumn{5}{|l|}{ Reasons for not using contraceptives ${ }^{3}$} \\
\hline Want more children & $66(32.4 \%)$ & $96(43.8 \%)$ & & \\
\hline No sexual intercourse & $63(30.9 \%)$ & $42(19.2 \%)$ & & 0.08 \\
\hline Religious reason & $23(11.3 \%)$ & $23(10.5 \%)$ & & \\
\hline Not accepted by the family & $11(5.4 \%)$ & $11(5 \%)$ & & \\
\hline Cannot access to contraceptive services & $5(2.5 \%)$ & $3(1.4 \%)$ & & \\
\hline
\end{tabular}

${ }^{1}$ Mean (SD). ${ }^{2}$ Number (\%). ${ }^{3}$ Each participant may have more than one reason for not using contraception. $\mathrm{CI}=$ confidence interval.

Table 3 shows factors significantly correlated with the knowledge scores obtained from the univariate and multivariate analyses. Higher education and higher income level were positively correlated with higher knowledge scores ( $>13$ was used as the cut-off level for high knowledge). However, only higher educational

Table 3. Variables correlated with the knowledge scores from univariate and multivariate logistic regression analysis

\begin{tabular}{|c|c|c|c|c|}
\hline Variables & $\begin{array}{c}\text { Crude odds ratio } \\
\text { (95\% confidence interval) }\end{array}$ & $P$ & $\begin{array}{c}\text { Adjusted odds ratio } \\
\text { (95\% confidence interval) }\end{array}$ & $P$ \\
\hline \multicolumn{5}{|l|}{ Geographical residence } \\
\hline Bangkok & $1.28(0.87,1.87)$ & 0.22 & & \\
\hline Southernmost provinces & 1 & & & \\
\hline \multicolumn{5}{|l|}{ Age (years) } \\
\hline$<35$ & 1 & 0.14 & & \\
\hline$\geq 35$ & $1.75(0.83,3.68)$ & & & \\
\hline \multicolumn{5}{|l|}{ Education } \\
\hline Below Bachelor's degree & 1 & 0.001 & 1 & 0.003 \\
\hline Equal/ higher than a Bachelor's degree & $2.06(1.39,3.05)$ & & $1.84(1.23,2.78)$ & \\
\hline \multicolumn{5}{|l|}{ Income (Thai baht) } \\
\hline$<5,000$ & 1 & 0.02 & 1 & 0.19 \\
\hline $5,000-20,000$ & $1.79(1.09,2.94)$ & & $1.51(0.91,2.52)$ & \\
\hline$>20,000$ & $2.50(1.25,5.00)$ & & $1.83(0.88,3.80)$ & \\
\hline \multicolumn{5}{|l|}{ Marital status } \\
\hline Single & 1 & 0.06 & & \\
\hline Married & $1.60(1.08,2.37)$ & & & \\
\hline Undisclosed & $1.55(0.38,6.53)$ & & & \\
\hline \multicolumn{5}{|l|}{ Current number of children } \\
\hline 0 & 1 & 0.25 & & \\
\hline 1 & $1.08(0.66,1.77)$ & & & \\
\hline 2 & $1.73(0.99,3.02)$ & & & \\
\hline 3 & $1.59(0.79,3.22)$ & & & \\
\hline$\geq 4$ & $1.01(0.42,2.45)$ & & & \\
\hline
\end{tabular}


level was correlated independently with higher knowledge scores. In Table 4, only higher knowledge score was correlated independently with the presence of a higher attitude score ( $>15$ was used as the cutoff level to indicate that the person had a more positive attitude towards contraception). Table $\mathbf{5}$ showed that lower income level and having fewer children were correlated independently with a history of having ever used contraception.

Table 4. Variables correlated with the attitude score from univariate and multivariate logistic regression analysis ${ }^{1}$

\begin{tabular}{|c|c|c|c|c|}
\hline Variables & Crude odd ratio $(95 \% \mathrm{CI})$ & $P$ & Adjusted odd ratio $(95 \% \mathrm{CI})$ & $P$ \\
\hline \multicolumn{5}{|l|}{ Geographical residence } \\
\hline Bangkok & $1.09(0.73,1.63)$ & 0.68 & & \\
\hline Southernmost provinces & 1 & & & \\
\hline \multicolumn{5}{|l|}{ Age (years) } \\
\hline$<35$ & 1 & 0.04 & 1 & 0.05 \\
\hline$\geq 35$ & $2.14(1.06,4.33)$ & & $2.01(0.99,4.10)$ & \\
\hline \multicolumn{5}{|l|}{ Education } \\
\hline Below Bachelor's degree & 1 & 0.78 & & \\
\hline Equal/ higher than a Bachelor's degree & $1.06(0.70,1.59)$ & & & \\
\hline \multicolumn{5}{|l|}{ Income (Thai baht) } \\
\hline$<5,000$ & 1 & 0.70 & & \\
\hline $5,000-20,000$ & $1.04(0.64,1.71)$ & & & \\
\hline$>20,000$ & $1.35(0.65,2.82)$ & & & \\
\hline \multicolumn{5}{|l|}{ Marital status } \\
\hline Single & 1 & 0.70 & & \\
\hline Married & $1.19(0.78,1.79)$ & & & \\
\hline Undisclosed & $0.89(0.21,3.84)$ & & & \\
\hline \multicolumn{5}{|l|}{ Current number of children } \\
\hline 0 & 1 & 0.29 & & \\
\hline 1 & $0.91(0.55,1.52)$ & & & \\
\hline 2 & $1.74(0.94,3.21)$ & & & \\
\hline 3 & $1.13(0.54,2.38)$ & & & \\
\hline$\geq 4$ & $0.97(0.40,2.39)$ & & & \\
\hline \multicolumn{5}{|l|}{ Ritual prayer (salat) } \\
\hline $1-4$ times & 1 & 0.64 & & \\
\hline 5 times & $1.03(0.66,1.63)$ & & & \\
\hline Others & $0.67(0.26,1.71)$ & & & \\
\hline \multicolumn{5}{|l|}{ Denominations of Islam n (\%) } \\
\hline Sunni & 1 & 0.81 & & \\
\hline Shia & $0.98(0.33,2.92)$ & & & \\
\hline Others & $0.81(0.44,1.52)$ & & & \\
\hline \multicolumn{5}{|l|}{ Fasting during the month of Ramadan (sawm) } \\
\hline$<7$ & 1 & 0.77 & & \\
\hline $7-13$ & $0.96(0.20,4.72)$ & & & \\
\hline $14-20$ & $0.62(0.15,2.52)$ & & & \\
\hline $21-27$ & $0.68(0.17,2.70)$ & & & \\
\hline $28+$ & $0.82(0.21,3.21)$ & & & \\
\hline \multicolumn{5}{|l|}{ Alms tax (zakat) } \\
\hline Ever in the past year & 1 & 0.28 & & \\
\hline Never in the past year & $0.62(0.26,1.48)$ & & & \\
\hline \multicolumn{5}{|l|}{ Pilgrimage to mecca (hajj) } \\
\hline Ever in the past year & 1 & 0.73 & & \\
\hline Never in the past year & $1.21(0.42,3.50)$ & & & \\
\hline \multicolumn{5}{|l|}{ Knowledge score ${ }^{1}$} \\
\hline$\leq 13$ & 1 & 0.005 & 1 & 0.007 \\
\hline$>13$ & $1.82(1.20,2.77)$ & & $1.78(1.17,2.71)$ & \\
\hline
\end{tabular}

${ }^{1}$ A mean score of 13 was used as the cut-off level to differentiate between high $(>13)$ and poor $(\leq 13)$ knowledge $\mathrm{CI}=$ confidence interval 
Table 5. Variables correlated with contraceptive use from univariate and multivariate logistic regression analysis

\begin{tabular}{|c|c|c|c|c|}
\hline Variables & Crude odd ratio $(95 \% \mathrm{CI})$ & $\boldsymbol{P}$ & Adjusted odd ratio $(95 \% \mathrm{CI})$ & $\boldsymbol{P}$ \\
\hline \multicolumn{5}{|l|}{ Geographical residence } \\
\hline Bangkok & $1.58(1.06,2.35)$ & \multirow[t]{2}{*}{0.02} & $1.78(0.98,3.22)$ & \multirow[t]{2}{*}{0.05} \\
\hline Southernmost provinces & 1 & & 1 & \\
\hline \multicolumn{5}{|l|}{ Age (years) } \\
\hline$<35$ & 1 & \multirow[t]{2}{*}{0.05} & & \\
\hline$\geq 35$ & $0.49(0.24,1.00)$ & & & \\
\hline \multicolumn{5}{|l|}{ Education } \\
\hline Below Bachelor degree & 1 & \multirow{2}{*}{0.61} & & \\
\hline Equal/higher than a Bachelor degree & $1.11(0.75,1.65)$ & & & \\
\hline \multicolumn{5}{|l|}{ Income (Thai baht) } \\
\hline$<5,000$ & 1 & \multirow[t]{3}{*}{0.001} & 1 & \multirow[t]{3}{*}{0.02} \\
\hline $5,000-20,000$ & $0.37(0.23,0.60)$ & & $0.45(0.25,0.79)$ & \\
\hline$>20,000$ & $0.41(0.21,0.83)$ & & $0.67(0.29,1.54)$ & \\
\hline \multicolumn{5}{|l|}{ Marital status } \\
\hline Single & 1 & \multirow[t]{3}{*}{0.001} & 1 & \multirow[t]{3}{*}{0.59} \\
\hline Married & $0.39(0.25,0.59)$ & & $0.81(0.49,1.35)$ & \\
\hline Undisclosed & $0.69(0.16,2.95)$ & & $0.56(0.11,2.88)$ & \\
\hline \multicolumn{5}{|l|}{ Current number of children } \\
\hline 0 & 1 & \multirow[t]{5}{*}{0.001} & 1 & \multirow[t]{5}{*}{0.001} \\
\hline 1 & $0.13(0.08,0.23)$ & & $0.17(0.09,0.30)$ & \\
\hline 2 & $0.09(0.05,0.17)$ & & $0.09(0.05,0.20)$ & \\
\hline 3 & $0.11(0.05,0.25)$ & & $0.12(0.05,0.29)$ & \\
\hline$\geq 4$ & $0.09(0.03,0.26)$ & & $0.10(0.03,0.32)$ & \\
\hline \multicolumn{5}{|l|}{ Ritual prayer (salat) } \\
\hline $1-4$ times & 1 & \multirow[t]{3}{*}{0.02} & 1 & \multirow[t]{3}{*}{0.42} \\
\hline 5 times & $0.60(0.39,0.93)$ & & $1.03(0.52,2.05)$ & \\
\hline Others & $0.27(0.09,0.85)$ & & $0.42(0.11,1.64)$ & \\
\hline \multicolumn{5}{|l|}{ Denominations of Islam n (\%) } \\
\hline Sunni & 1 & \multirow[t]{3}{*}{0.18} & & \\
\hline Shia & $2.59(0.90,7.44)$ & & & \\
\hline Others & $0.86(0.46,1.63)$ & & & \\
\hline \multicolumn{5}{|c|}{ Fasting during the month of Ramadan (sawm) } \\
\hline$<7$ & 1 & 0.02 & 1 & 0.52 \\
\hline $7-13$ & $1.42(0.24,8.48)$ & & $0.89(0.13,6.18)$ & \\
\hline $14-20$ & $5.01(1.01,24.80)$ & & $1.89(0.33,10.74)$ & \\
\hline $21-27$ & $2 . .68(0.55,12.95)$ & & $1.41(0.25,8.11)$ & \\
\hline $28+$ & $2.30(0.48,10.96)$ & & $1.91(0.35,11.23)$ & \\
\hline Alms tax (zakat) & & & & \\
\hline Ever in the past year & 1 & 0.02 & 1 & 0.21 \\
\hline Never in the past year & $2.57(1.19,5.54)$ & & $1.82(0.71,4.70)$ & \\
\hline Pilgrimage to mecca (hajj) & & & & \\
\hline Ever in the past year & 1 & 0.39 & & \\
\hline Never in the past year & $1.53(0.58,4.06)$ & & & \\
\hline Knowledge score ${ }^{1}$ & & & & \\
\hline$\leq 13$ & 1 & 0.57 & & \\
\hline$>13$ & $0.89(0.60,1.33)$ & & & \\
\hline Attitude scores ${ }^{2}$ & & & & \\
\hline$<15$ & 1 & 0.10 & & \\
\hline$\geq 15$ & $0.71(0.47,1.07)$ & & & \\
\hline
\end{tabular}

\footnotetext{
${ }^{1}$ A mean score of 13 was used as the cut-off level to differentiate between high $(>13)$ and poor $(\leq 13)$ knowledge ${ }^{2} \mathrm{~A}$ mean score of 15 was used as the cut-off level to differentiate between positive $(>15)$ and negative $(\leq 15)$ attitudes toward contraception
} 


\section{Discussion}

The results of the present study show that knowledge and attitude scores between Thai Muslim participants living in Bangkok and those living in the southernmost provinces are comparable. However, a higher proportion of participants who lived in the southernmost provinces used contraceptives. When a multivariate regression model was used to adjust for other variables, the women's geographical residence was not associated with higher knowledge and attitude scores, or contraceptive practices. This finding is by contrast with the results of the Thailand 2009 Reproductive Health Survey, which showed that contraceptive practice was lowest among women in the southern part of Thailand [1]. The discrepancy may be the result of the different study population used. Muslim women participated in the present study whereas the previous survey included all reproductive aged women from all religions including Buddhists. The discrepancy may be a consequence of the areas sampled, because most of the participants from the southernmost provinces were acquired from urban areas.

The present study also demonstrated that higher education and higher income were independent factors associated with knowledge of contraceptives. A higher educational level may help women understand health-related issues better than those with a lower educational level, while a higher income may provide the women with more opportunities to access health information [11]. Similarly, a communitybased cross-sectional KAP study conducted in a predominantly Muslim community of rural Kashmir found that educational level and female literacy were associated with awareness of contraception [12]. Another KAP study conducted in a predominantly (88\%) Muslim region (Kashmir) found that women with good knowledge had positive attitude towards contraception [13]. Similarly, the present study found that a high knowledge score was independently associated with a positive attitude towards contraception. It is possible that the questions regarding contraception and its impact on women's health used in this study may have contributed to this finding. However, neither high knowledge nor high attitude scores in this study were significantly associated with contraceptive practices. The variables independently associated with contraceptive practices were fewer children and lower income level. This is consistent with the hypothesis that women with lower income will want to restrict the number of children they have in their family to maintain and sustain a good quality of life, thus having to use contraception. Economic constraints and perception of a small family may improve awareness of contraception [13].

By contrast, being Muslim was not associated with KAP of contraception. However, the authors noticed that the religious beliefs and practices between those who lived in Bangkok and the southernmost provinces were slightly different. For example, most of the participants from the southernmost border provinces could achieve the ritual prayer (salat) whereas those from Bangkok could not. This may indicate different lifestyles of the women, which may impact their religious practices, but not KAP of contraception.

Other factors that may affect KAP of contraception were considered, such as future plans for having children. This factor was included in the multivariate model to limit the effects of the confounding factors. Thus, one of the limitations of this study is that not all of the confounding factors may have been eliminated during the analysis. Another limitation of the study is its cross-sectional design. Cause and effect cannot be ascertained by this type of design.

A strength of this study was its high response rate. The success of the study was a result of the careful planning of the data collection. For example, questions pertaining to the women's rituals and practices are very sensitive and difficult to assess. To overcome this barrier, self-administered questionnaires were used and confidentiality was emphasized during the collection of the data. Moreover, women may not be as forthcoming when approached by strangers so the study used only female research assistants who worked in the regions and were familiar with the participants. To our knowledge, this study is the first in Thailand to report KAP of contraception by Thai Muslim women from the southernmost border provinces.

\section{Conclusion}

Among Thai Muslim women, geographical location of residence was not significantly associated with knowledge, attitudes, and contraceptive practices. However, this present study revealed that college-level education and higher income level were independently associated with contraceptive knowledge. Favorable attitude was independently associated with higher 
contraceptive knowledge, whereas fewer children and lower income level were independently associated with contraceptive practices.

\section{Conflict of interest statement}

The authors declare that there is no conflict of interest in this research.

\section{Acknowledgments}

This study could not have been completed without the contribution and cooperation of the Narathiwat Rachanakarin Hospital, Reso Hospital, Pattani Hospital, Yala Hospital, and Bangkok Health Center. Mrs. Nasreeya Saedorma, Mrs. Chamaiporn Sinthuuthai, Ms. Romerra Maing, Mrs. Kordeyah Mahamad, our research nurses, and Dr. Penkae Dangsuwan were instrumental in gathering the data. We thank Wasan Panyasang and Thammasin Ingviya for the statistical analyses. We also thank June Ohata for proof reading and editing the manuscript. Somsook Santibenchakul is currently a Master's degree student in public health at the University of Hawai'i under the East-West Center Endowed and Named Scholarships from the East-West Center, HI, USA. This work was presented in part by Somsook Santibenchakul as an oral presentation Knowledge, Attitudes, and Practices of contraception among Thai Muslim women living in Bangkok and the Southernmost provinces of Thailand as part of the 15th East-West Center International Graduate Student Conference on the Asia-Pacific Region at the Imin International Conference Center, Honolulu, HI, USA on February 11-13, 2016.

\section{References}

1. Thai National Statistical Office. National Reproductive Health Survey. [online] 2009. [cited 2015 Aug 7]. Available from: http://service.nso.go.th/ nso/nsopublish/themes/files/fertility/fertilityFull.pdf

2. Finer LB, Henshaw SK. Disparities in rates of unintended pregnancy in the United States, 1994 and 2001. Perspect Sex Reprod Health. 2006; 38:90-6.

3. Thai National Statistical Office. Executive Summary.
The 2011 Survey on status of society and culture. [online] 2011. [cited 2015 August 7]. Available from: http://web.nso.go.th/en/survey/data_survey/570703_ Survey_\%20on_\%20Status_\%20of_\%20Societ_ 11.pdf

4. Smuseneto A. Reproductive health among Thaimuslim in the southernmost border of Thailand. 1st International Conference on Innovation and Sustainability; April 3-4, 2013; Kuala Lumpur, Malaysia. UUM Repository: Universiti Utara Malaysia; 2013.

5. Chayovan N, Hermalin AI, Knodel J. Measuring accessibility to family planning services in rural Thailand. Stud Fam Plann. 1984; 15:201-11.

6. Omran AR. Family planning in the legacy of Islam. New York: Routledge; 1992.

7. Hospital Statistics: King Chulallongkorn Memorial Hospital B, Thailand. Rate of multiparity among Thai Muslim 2013.

8. Hospital Statistics: Narathiwat Racha Nakarin Hospital $\mathrm{N}$, Thailand. Rate of multiparity among Thai Muslim 2011.

9. Kaye K, Suellentrop K, Sloup C. The fog zone: how misperceptions, magical thinking, and ambivalence put young adults at risk for unplanned pregnancy. Washington DC: The National Campaign to Prevent Teen and Unplanned Pregnancy; 2009.

10. World Health Organization Department of Reproductive Health and Research (WHO/RHR) and Johns Hopkins Bloomberg School of Public Health/ Center for Communication Programs (CCP) KfHP. Family planning: a global handbook for providers (2011 update). Baltimore and Geneva: CCP and WHO; 2011.

11. National Network of Libraries of Medicine. Health Literacy. [online] 2013. [cited 2015 August 12]. Available from: http://nnlm.gov/outreach/consumer/hlthlit.html

12. Hayat H, Khan PS, Imtiyaz B, Hayat G, Hayat R. Knowledge, attitude and practice of contraception in rural Kashmir. J Obstet Gynaecol India. 2013; 63:410-4.

13. Naqvi S, Hashim N, Zareen N, Fatima H. Knowledge, attitude and practice of parous women regarding contraception. J Coll Physicians Surg Pak. 2011; 21: 103-5. 